\title{
LA SEGUNDA MUERTE DE DON QUIJOTE COMO RESPUESTA DE CERVANTES A AVELLANEDA
}

Un aspecto del Quijote que quizás no haya recibido la atención que merece es el de presentarse como una obra escrita en dos partes, cada una de las cuales termina con la muerte del protagonista. Cervantes mismo explicó esta particularidad como consecuencia de su reacción al Quijote apócrifo de Avellaneda. Descontento con la deformación de su obra por ese "escritor fingido y tordesillesco" para quien no fue "carga de sus hombros, ni asunto de su resfriado ingenio" ", el autor original decidió llevar al hidalgo manchego a un fin que cerraría el paso a nuevas continuaciones de sus andanzas. Para lograr su propósito, pensó ofrecer al lector una segunda parte auténtica "cortada del mismo artífice y del mesmo paño que la primera" (V, 22) con un "don Quijote dilatado, y finalmente muerto, y sepultado, porque ninguno se atreva a levantarle nuevos testimonios" "2. Lo anunciado así con estas palabras en el Prólogo en efecto tocó la nota del último párrafo de la novela en que Cervantes dejó a don Quijote "en la fuesa donde real y verdaderamente yace tendido de largo a largo, imposibilitado

1 Miguel de Gervantes, El ingenioso hidalgo Don Quijote de la Mancha, ed. de F. Rodriguez Marín, 8 ts., Clás., Cast., t. 8, p. 334. En adelante indicamos tomo y página al citar esta edición.

2 Corregimos la puntuación de la edición que utilizamos, repetida en todas las ediciones modernas que hemos podido consultar. En todas ellas se lee: "don Quijote dilatado, y, finalmente, muerto, y sepultado..." (V, 22) . Quitamos la segunda y tercera coma en conformidad con la edición príncipe (véase la edición facsímil publicada por Alfaguara, The Hispanic Society y Papeles de Son Armadans en Palma de Mallorca, 1968, 2 ts., t. 2, Prólogo al lector, sin paginación), no por vano escrúpulo de erudición sino para restaurar el sentido de lo que Cervantes escribió originalmente. En el contexto en que aparece, "finalmente muerto" quiere decir "definitivamente muerto", mientras que "finalmente, muerto" equivaldría a "al fin, muerto", como se ve en la traducción de J. M. Cohen: "I present you with the knight at greater length and, in the end, dead and buried" (subrayado nuestro; cf. ed. Penguin Books, 1956, p. 470). 
de hacer tercera jornada y salida nueva" mientras desaconsejó a Avellaneda de querer volver a sacarlo para nuevas aventuras en Castilla la Vieja "contra todos los fueros de la muerte" (VIII, 334-335) ${ }^{3}$.

La insistencia cervantina en lo definitivo de la segunda muerte de Don Quijote pudiera desecharse como pura retórica dirigida contra su torpe imitador. Pero el lector de Cervantes ya sabe que no es siempre tan fácil fijar el blanco de sus tiros literarios. Aquí, terminada la lectura de la novela, quizás cabría reflexionar sobre si Cervantes, además de advertir a su rival, también quería llamar la atención al procedimiento suyo en llevar a don Quijote a la muerte esta vez de una manera notable que verdaderamente desanimaría a otro Avellaneda de querer volver a resucitarlo. Si éste fuera el caso, habría que determinar si Cervantes comenzó la composición de la Segunda Parte con tal proyecto en la mente o si se le ocurrió tardíamente, al acercarse al capítulo 59 cuando, según la opinión común, tropezó por primera vez con la obra avellanedesca. ¿Podría ser que Cervantes, habiendo aparentemente rechazado la idea de narrar nuevas andanzas de su caballero al terminar la Primera Parte de su libro, hubiera sido empujado a volver al asunto por la deformación de su obra por Avellaneda? ¿Sería que esa deformación, repugnante como fue para Cervantes, le hizo reflexionar sobre la obra que había publicado en 1605 para descubrir en ella posibilidades cuyo desarrollo había de conducirle a una nueva muerte de su protagonista? Al llevar a cabo tal proyecto, lograría subrayar la trivialidad del Quijote de Avellaneda, una figura absurda incapaz de soportar el peso grave de la muerte. A la vez, trazando el camino a la tumba de su hidalgo en un proceso del desarrollo de su existencia, otorgaría una nueva importancia a su muerte que hacía falta en la Primera Parte, donde el hecho de haber llegado don Quijote al final de su vida no fue más que un suceso recordado en un epitafio.

Apenas hace falta confesar que todo lo que se está insinuando está en desacuerdo con la ya notada opinión respecto al descubrimiento tardio por Cervantes del Quijote apócrifo, la cual parece justificada por consideraciones cronológicas. En efecto, el plazo que separó la publicación de la obra de Avellaneda de la terminación del manuscrito cervantino no pudo ser mayor que ocho meses

3 Recuérdese que Avellaneda terminó el Quijote suyo con la noticia de que su loco entreverado salió de la casa del Nuncio y "se fue la vuelta de Castilla la Vieja" en una nueva serie de "estupendas y jamás oídas aventuras". Véase Alonso Fernández de Avellaneda, El ingenioso hidalgo don Quijote de la Mancha, ed. de F. García Salinero, Clás. Castalia, Madrid, 1971, p. 463. En lo que sigue citamos capítulo y página de esta edición. 
y probablemente no más que cinco o seis meses ${ }^{\ddagger}$. No parece verosímil que Cervantes hubiera podido en tan poco tiempo conocer a fondo el libro de su rival y también componer la Segunda Parte en reacción a ello. Sin embargo, el problema tiene por lo menos dos soluciones posibles. Cervantes pudo conocer el Quijote de Avellaneda antes de su publicación, en forma manuscrita. $O$, si se prefiere, aceptando la idea de haber encontrado la imitación tarde, cuando ya estaba avanzada su propia continuación del Quijote, Cervantes pudo haber vuelto a rehacer mucho de lo que ya había escrito ${ }^{5}$. En este caso, también habría que considerar la Segunda Parte del Quijote como derivada, por lo menos en parte, de la lectura del libro de Avellaneda.

Sea como sea la solución del problema cronológico, nos confronta con un hecho innegable que parece confirmar lo que vamos sugiriendo respecto a la relación entre el Quijote apócrifo y la continuación por Cervantes de su propia obra. El hecho es que encontramos un número extraordinario de coincidencias entre las dos obras que sería muy difícil poner a la cuenta del puro azar. $\mathrm{Y}$ estas coincidencias - en realidad puntos de contacto tangenciales que Cervantes arrebata para utilizarlos para sus propios finescomienzan a acumularse desde las primeras palabras de la Segunda Parte cervantina. Así es que "El sabio Alisolán, historiador no menos moderno que verdadero..." con que comienza Avellaneda $(I, 57)$ resuena inmediatamente en las primeras palabras de Cervantes: "Cuenta Cide Hamete Benengeli..." (V, 25). Y aunque todavía no estamos para analizar detalladamente las divergencias a que dan lugar estos puntos de contacto, quizás sea conveniente anticiparlas desde ahora notando que el Alisolán "moderno" y "verdadero" de Avellaneda en seguida resulta ser morisco, "... siendo expelidos los moros agarenos de Aragón, de cuya nación él decendía..." (I, 57). Cervantes, por su parte, insiste en devolver

4 Sabemos que el manuscrito de Avellaneda no se publicó antes del 4 de julio de 1614, fecha en que recibió la licencia de imprimirse (véase la ed. de García Salinero, p. 49) . La primera aprobación del libro de Cervantes, firmada por el licenciado Márquez Torres, está fechada ocho meses más tarde, el 27 de febrero, 1615 (véase la edición facsímil citada, t. 2, f. 4v). Si contamos por lo menos dos o tres meses para la impresión del libro de Avellaneda, después de otorgada la licencia, quedan seis o cinco meses como posible intervalo entre la publicación de la primera obra y la terminación del manuscrito de la segunda.

5 Esta posibilidad quedaría más de acuerdo con el hecho de que ya en 1613, en el prólogo a las Novelas ejemplares, Cervantes estaba prometiendo presentar "con brevedad, dilatadas las hazañas de don Quijote" (cf. la ed. de F. Gutiérrez, Las Américas, New York, 1962, t. 1, p. 9); a menos que resulte que ya en 1613 pudo Cervantes ver el manuscrito terminado de Avellaneda. 
la narración de las hazañas de don Quijote a su moro de la Primera Parte, ni moderno ni siempre verdadero, detalle incómodo para el hidalgo: “...desconsolóle pensar que su autor era moro, según aquel nombre de Cide, y de los moros no se podía esperar verdad alguna, porque todos son embelecadores, falsarios y quimeristas" $(\mathrm{V}, 66)$. Este giro que Cervantes da al comienzo avellanedesco le sirve para un propósito cuyo sentido trataré de sugerir.

Volviendo a las notas comunes que comparten los dos Quijotes desde sus primeros párrafos, encontramos que pocos renglones más adelante los dos autores están de acuerdo sobre la manera de curar al hidalgo de su locura. Mientras Avellaneda cuenta que "no con pequeño regalo de pistos y cosas conservativas y sustanciales, le volvieron poco a poco a su natural juicio" (I, 58), Cervantes encarga "regalarle, dándole a comer cosas confortativas y apropriadas para el corazón y el celebro" (V, 25). En seguida hacen constar ambos escritores que el tratamiento que han recetado da indicios de ser eficaz. Las mujeres que atienden al Quijote de Cervantes "echaban de ver que su señor por momentos iba dando muestras de estar en su entero juicio" (V, 25) y Avellaneda cuenta que el hidalgo suyo "empezó con mucha instancia a rogar a Madalena, su sobrina, que le buscase algún buen libro" y con la lectura de los libros que le entregan "fue reducido dentro de seis meses a su antiguo juicio" (I, 58-59) .

Hasta aquí, se podría considerar que lo que tienen en común las dos obras sería casual o sencillamente normal al reanudar cada autor la narración de las aventuras de Quijote -aunque tal explicación se hace un poco insegura al darnos cuenta de que los mencionados detalles aparecen dispuestos en el mismo orden en las dos narraciones. $\mathrm{Y}$, lo que es más, con estos primeros párrafos apenas ha comenzado a desplegarse una larga serie de puntos en que se tocan ambas continuaciones del Quijote. Una rapidisima primera ojeada, limitada a lo más evidente, destacaría, entre muchos otros acercamientos entre las dos obras, los siguientes: en ambos libros, Sancho pide un sueldo mensual como condición de acompañar a su dueño en una tercera salida (Avellaneda, cap. II; Cervantes, cap. VII) ; los dos autores enredan a don Quijote en un encuentro con una compañía de representantes (Avellaneda, cap. XXVI; Cervantes, cap. XI) ; si Avellaneda hace intervenir a don Quijote en la acción de una comedia en que defiende la honra de la reina de El testimonio vengado de Lope (cap. XXVII), Cervantes hace que el Quijote suyo irrumpa en la acción del retablo de Maese Pedro para defender a Melisendra y Gaiferos (cap. XXVI); la carta que el Sancho avellanedesco escribe a su esposa desde el palacio de don Carlos (cap. XXXV) tiene su contraparte en la carta que escribe 
el Sancho de Cervantes a la suya desde el palacio del duque (cap. XXXV); en efecto, todo el desarrollo por Cervantes de la estancia de don Quijote en la corte de los duques ${ }^{6}$, incluso los detalles de sus encuentros con figuras encantadas (caps. XXXIV-LVII) parece ser una adaptación de la estancia del loco hidalgo de Avellaneda en palacios nobles donde se encuentra con Bramidán de Tajayunque (primero en Zaragoza, cap. XII, y más tarde en Madrid, caps. XXXI-XXXV) ${ }^{7}$. Todos estos puntos de contacto entre las dos obras, hay que subrayarlo, ocurren antes de ese capítulo LIX de la Segunda Parte de Cervantes en que se hace la primera mención del Quijote apócrifo. Además de esto, cabe notar que, con la excepción de las visitas de los dos Quijotes a casas nobles (en la obra de Avellaneda ocurren en los primeros capítulos y luego en los últimos), todos los detalles que hemos señalado quedan dispuestos en el mismo orden narrativo en los dos libros. En fin, en vista de tal paralelismo, ¿sería completamente descabellado imaginar a Cervantes sentado al escritorio compulsando páginas de la novela avellanedesca mientras componía la continuación de su Quijote?

No estaba muy alejado de tal imaginación Ramón Menéndez Pidal cuando declaró, hace más de medio siglo, que Avellaneda "sirvió de fuente de inspiración para Cervantes cuando escribió la segunda parte de su novela" y que "Cervantes tuvo alguna noticia bastante detallada de la obra de su competidor antes de redactar el capítulo LIX, en donde expresamente alude ya a ella, y que marca el momento en que ella hubo de salir a luz" :. Aunque don Ramón no sacó las consecuencias de su intuición que nos interesa desarrollar aquí, pudiera servir de epígrafe para este trabajo su conclusión de que "La superioridad de la segunda parte del Qui. jote... se puede achacar en mucho a Avellaneda. Hay fuentes inspiradoras por repulsión, que tienen tanta importancia, o más, que las que operan por atracción" ". En nuestros días Fernando García

${ }^{6}$ Hay que recordar que en el capítulo XXI de la Primera Parte (II, 177 ss.), don Quijote se negó a entrar en la corte antes de ganar fama por sus hazañas

7 Se puede añadir que en cada libro es del encuentro en la corte con una figura de encantamiento que surge la tarea principal de don Quijote en la obra: en Avellaneda, vencer a Tajayunque; en Cervantes, desencantar a Dulcinea.

8 "Un aspecto en la elaboración del Quijote" que Pidal incluyó en su De Cervantes y Lope de Vega, Buenos Aires, 1940, p. 41. En su forma original este estudio fue un discurso que don Ramón leyó en 1920.

9 Op. cit., p. 42. STEPhen Gilman rechazó esta opinión de don Ramón con el argumento principal de que "Si Cervantes hubiera poseído un ejemplar del Quijote apócrifo mientras escribía la Segunda Parte, ¿no habría más semejanzas literales a lo largo del libro?" (véase su libro Cervantes y Avellaneda: estudio de una imitación, México, 1951, p. 170). También. en vista de algu- 
Salinero, en su muy valiosa y ya citada edición del Quijote apócrifo, abrió por un momento la posibilidad de explorar lo que Pidal había sugerido, observando, a propósito del episodio del retablo de Maese Pedro: "no es imposible. . estuviese inspirado en el capítulo XXVII del de Avellaneda, en el cual unos representantes ensayan «la grave comedia de El testimonio vengado, del insigne Lope de Vega Carpio»". Pero García Salinero se limita a plantearlo como un problema de plagio sin solución -pues " $\dot{\alpha}$. quién puede asegurar cuál es el original y cuál el plagio?”- y concluye arbitrariamente, "optamos por creer que Cervantes no conoció el Quijote imitado hasta el momento en que él mismo lo confiesa en el capítulo LIX" (p. 23). Nos parece que tal planteamiento del problema de las coincidencias entre las dos obras, en que se llega a hablar de un Avellaneda que "entró a saco abundantemente en el Quijote original" o de un Cervantes quizás comprometido en un "hurto literario" (pp. 22, 23), desvía la atención de lo más interesante del asunto. En realidad, no se trata aquí de más plagio -ni de parte de Avellaneda ni de parte de Cervantes- que en el caso de un debate en que un polemista se apodera del argumento de su adversario para volverlo contra él mismo. Enfocada así la cuestión, se la puede examinar, no para decidir quién plagió a quién, sino para descubrir cómo cada autor se apoderó de materias encontradas en la obra del otro y las utilizó para sus propios propósitos, para

nas semejanzas entre las dos obras (p. 169) y después de tomar en cuenta consideraciones cronológicas (pp. 171-173), Gilman se inclinó a la posibilidad de que Avellaneda hubiera podido tener algún conocimiento de la segunda, además de la primera, parte de la novela cervantina cuando escribió su imitación del Quijote (pp. 174-176). Aunque esta sugestión no se puede descartar por imposible, tampoco convence, por lo menos a este lector, principalmente porque Avellaneda no se mete directamente con la Segunda Parte a pesar de ofrecerle ésta materia sobrada para hacerlo. Por ejemplo chubiera pasado en silencio una persona del temperamento de Avellaneda (tal como se revela en su Prólogo) las duras reprehensiones que le lanzó Cervantes por boca de don Quijote, consintiendo en muchas de cllas su propio Álvaro Tarfe? (VIII, 86 ss., 299 ss.). Sólo en el Prólogo hace Avellaneda lo que se podría considerar una referencia directa a la Segunda Parte corrantina, "...quéjesc de mi trabajo por la ganancia que le quito de su segunda parte" (ed. cit., p. 52). Y aun esto, en vez de indicar que Avellaneda tenía algún conocimiento de la obra de Cervantes, podría considerarse sencillamente un desafío retórico respecto a una segunda parte todavía inexistente que Cervantes podría sentirse tentado a escribir. Las otras referencias a la obra de Cervantes que se encuentran en el Prólogo de Avellaneda se dirigen más bien a la Primera quc a la Segunda Parte. Por último, parece argüir en favor de ser Cervantes conocedor de la obra de Avellaneda la manera de relacionarse los puntos de contacto entre ambos libros. Lo avellanedesco siempre se hace más complejo y más problemático al ser reelaborado por Cervantes, según trataremos de demostrar más adelante, con lo cual se saca la impresión de que es él quien cstá reaccionando contra lo que escribió su imitador. 
construir con ellas su propio "argumento literario" con que rebatir a su rival.

Si se acepta esta manera de estudiar no los plagios sino las coincidencias entre ambas obras, hace falta tener delante alguna idea de lo que se proponía cada autor en la composición de su libro porque a ello correspondería su utilización de esas coincidencias. Paradójicamente, se ofrece la posibilidad de distinguir entre los propósitos de Cervantes y Avellaneda precisamente cuando éste afirma en su Prólogo que "tenemos ambos un fin, que es desterrar la perniciosa lición de los vanos libros de caballerías" (p. 52). Con esto, parece creer estar de acuerdo con lo que había leído en el Prólogo de la Primera Parte cervantina respecto a llevar "la mira puesta a derribar la máquina mal fundada destos caballerescos libros" (I, 24). Pero el hecho es que la expresión avellanedesca toca una nota moralizante, ausente en la de Cervantes, que se dirige tanto al lector de los libros de caballerías como contra los libros mismos. La obra de Avellaneda resulta ser, después de todo, más anti-quijotesca que anti-caballeresca. Su blanco principal es el hidalgo vuelto loco por sus malas lecturas, por las cuales cae en el absurdo de pasearse por el mundo como un alucinado caballero andante. Cervantes pudo haber comenzado con un propósito moralizante parecido, pues también el hidalgo suyo "del mucho leer... vino a perder el juicio" y dio en "el más extraño pensamiento que jamás dio loco en el mundo" que fue el de hacerse caballero andante (I, 56-59). Pero, a pesar de comenzar así, el autor no tardó en desviarse de la censura moralizante de un Quijote loco para emprender el desarrollo de la problemática de su vida ${ }^{10}$. Lo que Cervantes llevó a cabo en la Primera Parte de su Quijote, le permitió aceptar la idea que le sugirió ese "amigo" del Prólogo de que había escrito una invectiva contra los libros de caballería con miras a derribar su "máquina mal fundada", una referencia a su arte literaria defectuosa si se entiende a la luz del enjuiciamiento del género por el canónigo en el capítulo XLVII de la novela (IV, 229-235).

Esta diferencia fundamental entre la obra cervantina y la de Avellaneda que vamos sugiriendo, se expresa literariamente en una de esas coincidencias que se encuentran antes del capítulo LIX de la Segunda Parte de Cervantes. En los capítulos XXXI y XXXII

10 No se refiere esto sólo a los obstáculos que encuentra don Quijote para realizar sus empresas. Más importante es la manera de jugarse la validez de lo que se propone hacer, por la cual se pone en tela de juicio la locura o la cordura del hidalgo y aun de varios otros personajes de la novela. Recuérdense asuntos como el encuentro de don Quijote y Cardenio, dos locos enamorados en Sierra Morena, y el andar por el monte del cura, vestido de las faldas de Micomicona, procurando hacer volver a don Quijote de las locas andanzas suyas. 
de ésta, Cervantes recuerda el encuentro del Quijote apócrifo con Mosén Valentín (cap. VII) en el encuentro de su Quijote con el eclesiástico en la corte de los duques. Avellaneda se sirvió del clérigo de Ateca para declarar los peligros en que se había metido don Quijote y lo que debía hacer para corregir la vida en que andaba. Así es que Mosén Valentín recibe al loco hidalgo en su casa para "advertirle a solas, de las puertas adentro de mi casa, cómo anda en pecado mortal, dejando la suya y su hacienda... andando por esos caminos como loco, dando nota de su persona y haciendo tantos desatinos" de manera que puede ser que alguna vez "le prenda la justicia, y no conociendo su humor, le castigue con castigo público y pública deshonra de su linaje". Y si ocurre que, tomado de su locura, quizás haya matado a alguien en la campaña, "le cogerá tal vez la Hermandad, que no consiente burlas, y le ahorcará, perdiendo la vida del cuerpo, y lo que peor es, la del alma" (VII, 130). Luego le aconseja Valentín lo que debe hacer: volver a casa y gastar su hacienda "en servicio de Dios y en hacer bien a pobres, confesando y comulgando a menudo, oyendo cada día su misa, visitando enfermos, leyendo libros devotos y conversando con gente honrada y, sobre todo, con los clérigos de su lugar, que no le dirán otra cosa de lo que yo le digo; y verá con esto cómo será querido y honrado, y no juzgado por hombre falto de juicio, como todos los de su lugar y los que le ven andar desa manera le tienen" (VII, 131). Como respuesta, don Quijote, loco de remate, toma a Valentín por el arzobispo Turpín, a quien reprende por su "pusilanimidad y cobardía" (VII, 132).

En la confrontación que Cervantes arma entre don Quijote y el eclesiástico, comienza quitando a éste la autoridad moral que Avellaneda prestó a Mosén Valentín. Le introduce como "un grave eclesiástico destos que gobiernan las casas de los príncipes; destos que, como no nacen príncipes, no aciertan a enseñar cómo lo han de ser los que lo son; destos que quieren que la grandeza de los grandes se mida con la estrecheza de sus ánimos" (VI, 243). Este eclesiástico no tiene nada de la benevolencia de Valentín. Más bien es un colérico deslenguado que pronuncia con acento envenenado los mismos avisos y consejos que el Quijote de Avellaneda recibió del clérigo de Ateca. "Y á vos, alma de cántaro", comienza el eclesiástico cervantino, "¿quién os ha encajado en el celebro que sois caballero andante y que vencéis gigantes y prendéis malandrines?... volveos a vuestra casa, y criad vuestros hijos, si los tenéis, y curad de vuestra hacienda, y dejad de andar vagando por el mundo, papando viento y dando que reir a cuantos os conocen y no conocen" (VI, 253). Es de este modo que lo que fue amonestación fraternal en Avellaneda se ha convertido aquí en una agresión contra la 
vida de don Quijote cuya respuesta verdaderamente, como dice Cervantes, "capítulo por sí merece" (VI, 253).

Tras aleccionar al clérigo cortesano sobre las "reprehensiones santas y bien intencionadas" que "mejor asientan sobre la blandura que sobre la aspereza", don Quijote comienza a regañarle por "sin tener conocimiento del pecado que se reprehende, llamar al pecador, sin más ni más, mentecato y tonto” y le demanda “¿por cuál de las mentecaterías que en mí ha visto me condena y vitupera, y me manda que me vaya á mi casa...?" (VI, 256). Y luego pasa al contraataque, destacando la superioridad de la vida suya en comparación con la del eclesiástico: “¿No hay más sino á trochemoche entrarse por las casas ajenas á gobernar sus dueños, y habiéndose criado algunos en la estrecheza de algún pupilaje, sin haber visto más mundo que el que puede contenerse en veinte o treinta leguas de distrito, meterse de rondón á dar leyes á la caballería y á juzgar de los caballeros andantes? ¿Por ventura es asumpto vano ó es tiempo mal gastado el que se gasta en vagar por el mundo, no buscando los regalos dél, sino las asperezas por donde los buenos suben al asiento de la inmortalidad?" (VI, 256-8). Concluye don Quijote disparando un último tiro contra el eclesiástico, a quien Cervantes habrá dejado en el anonimato quizás para abrazar en su figura todos los otros de su ralea: "Unos van por el ancho campo de la ambición soberbia; otros, por el de la adulación servil y baja; otros, por el de la hipocresía engañosa, y algunos, por el de la verdadera religión; pero yo, inclinado de mi estrella, voy por la angosta senda de la caballería andante, por cuyo ejercicio desprecio la hacienda, pero no la honra" (VI, 258).

El examen de este intercambio, en el que don Quijote deja malparado al eclesiástico cortesano, revela cuánto se ha alejado Cervantes del propósito moralizante de su rival ${ }^{11}$. A la vez, nos acerca a lo que ya se ha hecho el hilo conductor que ha de llevar al hidalgo manchego a la muerte en la Segunda Parte. Lo que se está jugando es la visión caballeresca de don Quijote, no como una enfermedad mental según pasa en la obra avellanedesca, sino como el problema de trazarse un proyecto de vida, de una existencia en que se engendrará como "hijo de sus obras". En este caso del encuentro con el clérigo, don Quijote ha salido bien, pero se ha visto obligado a defenderse de una manera radical que no tiene antecedentes en la Primera Parte pero sí los tiene en la Segunda. Los asaltos que sufre ahora no son como los golpes y las palizas que menudearon sobre él en la Primera Parte. Éstos son más penetran-

11 ¿Será una socarronería cervantina sellar en seguida el triunfo de don Quijote sobre su censor, haciendo que delante de los ojos de éste se nombre a Sancho gobernador de la prometida ínsula? (VI, 260-26I). 
tes, entran en la intimidad de su ser y le dejan en un vaivén entre incertidumbres y reafirmaciones de la validez de su vida. Es en esta dialéctica existencial que se desarrolla la Segunda Parte encaminada a la muerte definitiva de don Quijote, que ocurre precisamente cuando el hidalgo se desdice de su vida caballeresca. Queda por señalar cómo este camino se provecta con la mirada repetidamente puesta en el texto de Avellaneda.

Cervantes no tarda mucho en fijar el rumbo que ha de tomar la continuación de su novela. Para hacerlo se dirige primero al problema fundamental con el que le habría dejado la lectura del libro de Avellaneda: restablecer el sentido auténtico de la locura de su hidalgo. Si Avellaneda había comenzado con un Quijote en poco tiempo sanado de su locura y en seguida loco otra vez -según puede pasar en una verdadera enfermedad-, Cervantes ahora transforma esta alternación entre locura y cordura en un extraordinario equívoco que da el tono al desarrollo de su obra. Mientras que Avellaneda había anunciado la cura de su hidalgo que "olvidándose de las quimeras de los caballeros andantes, fue reducido dentro de seis meses a su antiguo juicio" (I, 58-59), Cervantes dejó la cuestión pendiente. Su Quijote "por momentos iba dando muestras de estar en su entero juicio" ( $V, 25)$ de modo que la visita que le hicieron el cura y el barbero fue para "hacerle experiencia de su mejoría, aunque tenían casi por imposible que la tuviese" ( $V$, 26). Esta nota problemática no se encuentra en el Quijote cuerdo de Avellaneda que lee vidas de santos y otros libros devotos, va a misa con el rosario en las manos, oye con mucha atención los sermones y ni se llama ya Quijote sino Martín Quijada. De tal cordura inequívoca vuelve a caer en su antigua demencia, igualmente indubitable, y emprende una salida en busca de aventuras que le descubren como una figura ridicula sin relieve ${ }^{12}$.

Por su parte, Cervantes se desvió de este procedimiento avellanedesco en que, efectivamente, se rompió la continuidad de la identidad quijotesca. El Quijote cervantino que se tiene por discreto y el otro disparatado se dan en la misma personalidad, sin solución de continuidad, y de ahí nace la problemática de su vida. Así, en la visita que recibe del cura y el barbero, les da cuenta de sí y de su salud "con mucho juicio y con muy elegantes palabras" $(V, 27) y$, sin la transformación radical de vida y costumbres que se vio en el Quijote de Avellaneda, el de Cervantes discurre sobre

12 Recuérdese que Avellaneda, la mirada siempre puesta en el fin suyo, hace que comience la reincidencia de don Quijote en la locura al traerle Sancho noticias de haber escuchado la lectura de un libro de caballería (I, 62). Las conversaciones con Álvaro Tarfe, que va a las justas de Zaragoza, y las armas que recibe de él, completan su reintegración en la locura caballeresca (I, 66-II, 81). 
cuestiones de estado y gobierno "con tanta discreción... que los examinadores creyeron indubitadamente que estaba del todo bueno y en su entero juicio" (V, 27). Pero luego, sin cambiar de postura y en perfecta consonancia con la manera en que se estaba portando, don Quijote se desliza a lo de acudir a los caballeros andantes del reino para librarse del peligro del Turco (V, 28-32).

En lo que sigue, es decisiva para sondear la profundidad de sentido que Cervantes quiere prestar a la locura de su hidalgo, la reacción de éste a lo que cuenta el barbero del loco de Sevilla, "por venir aquí como de molde" ( $V, 32)$. El manchego reconoce en seguida la insinuación del barbero con el cuento del sevillano que logró convencer a todos que estaba cuerdo y que en el momento de estar saliendo del manicomio declaró que no había que preocuparse por la amenaza del loco "Júpiter" de no llover en todo el distrito por tres años, pues "yo, que soy Neptuno, el padre y el dios de las aguas, lloveré todas las veces que se me antojare y fuere menester" (V, 38). En un primer movimiento, don Quiiote rechaza rotundamente la mal encubierta acusación del barbero (V. 39). Pero, al seguir reclamando las virtudes caballerescas que hacen falta para defeuder el reino $-\mathrm{a}$ los caballeros cortesanos actuales "autes les crnjen los damascos, los brocados y otras ricas telas que se visten que la malla con que se arman" $(V, 40)$ - acaba abrazando lo antes negado. Eu efecto, tauta es la necesidad de caballeros andantes que "si Júpiter, como ha dicho el Barbero, no lloviere, aquí estay ya, que lloveré cuando se me antaịare. Digo esto porque sepa el señor Bacía que le entiendo" ( $V, 42-43)$.

Esta manera de aceptar la calificación de su anhelo de vida caballeresca como "locura", separa al Quijote cervantino radicalmente de su contraparte apócrifa. En vez de presentarse como un loco, sujeto a curaciones y reincidencias en su mal, se ve proyectando una visión de vida que puede parecer ilusión pero cuya cordura esencial queda garantizada por la coherencia de esa visión y por la integridad con que don Quijote se dedica a ella. Tomar por locura la vida quijotesca y proponerse curarle de ella, trae consecuencias inesperadas y muy graves, tanto para el curandero como para don Quijote. Esto es lo que se descubre al pretender hacerlo Sansón Carrasco en el terreno quijotesco mismo, venciendo al hidalgo mano a mano en un combate caballeresco.

Aunque queda reservado para Carrasco, como el Caballero de la Blanca Luna, dar el golpe final que acaba con la carrera de don Quijote, esto sólo ocurre después de un largo recorrido en que el hidalgo va acumulando dudas e incertidumbres respecto a la vida caballeresca que lleva. En el capítulo II de la continuación de su novela, Cervantes da otro paso en el desarrollo de la vida pro- 
blemática de su protagonista, esta vez con el efecto de prepararle para vivir íntimamente las inseguridades que le van a afligir. Y otra vez, parece que Cervantes tiene la mirada puesta en el libro de Avellaneda. Éste había creado una escena cómica, casi grotesca, empujando a don Quijote otra vez a su locura con preocupaciones extravagantes por la facha que presentaba. Armado de las piezas que le había dejado Alvaro Tarfe, don Quijote comenzó a pasearse delante de Sancho buscando el reflejo de su figura gallarda en los ojos de su antiguo escudero: “¿Qué te parece, Sancho? ¿Estánme bien? ¿No te admiras de mi gallardia y brava postura?" (III, 88) . Entonces, mientras se paseaba por el aposento "haciendo piernas y continentes, pisando de carcaño y levantando más la voz y haciéndola más gruesa, grave y reposada" le sobrevino "un accidente tal en la fantasía que, metiendo con mucha presteza mano a la espada, se fue acercando con notable cólera a Sancho" (loc. cit.). En 10 que sigue, don Quijote ataca furiosamente a Sancho a quien demanda "las princesas y caballeros que, contra ley y razón, en este tu castillo tienes" (III, 89). El repentino volver en sí, cuando Sancho se rinde y promete hacer "todo eso que me dice" (III, 90), sólo sirve para destacar la absurda locura del hidalgo -sobre todo cuando confiesa que "todo era fingido" (III, 91) - que tiene su origen en la "perniciosa lición" de los libros de caballería.

De otro modo y para otros fines, Cervantes también presenta un episodio en el que su Quijote también se ve preocupado por su apariencia. Pero no es el reflejo de su figura gallarda que don Quijote busca en los ojos de Sancho sino "lo que dicen de mí por ese lugar" (V, 56). Así es que pide noticias sobre “¿En qué opinión me tiene el vulgo, en qué los hidalgos y en qué los caballeros? ¿Qué dicen de mi valentía, qué de mis hazañas y qué de mi cortesía? ¿Qué se platica del asumpto que he tomado de resucitar y volver al mundo la ya olvidada orden caballeresca?" $(V, 57)$. Es la primera vez en toda la novela cervantina, incluyendo la Primera Parte, que encontramos a don Quijote con preocupaciones de lo que se piensa de él y lo que aprende dista mucho de la idea que él se ha formado de sí mismo. Sin embargo, todavía sabe defenderse. Si Sancho le dice, entre otras cosas, que le tienen por "loco, pero gracioso... valiente, pero desgraciado... cortés, pero impertinente", no le extraña, pues "donde quiera que está la virtud en eminente grado, es perseguida" (V, 60-61). Respecto a esto, está en buena compañía. Lo mismo sufrieron Julio César, Alejandro Magno, Hércules y don Galaor, hermano de Amadís de Gaula.

Pero hay algo más grave. Anda por ahí un libro con el título de El ingenioso hidalgo don Quijote de la Mancha por un tal 
Cide Hamete Benengeli. Esto sí que deja a don Quijote desconsolado, según ya hemos notado, porque de los moros no se puede esperar más que mentiras. Si, como declara el hidalgo, "Una de las cosas... que más debe de dar contento á un hombre virtuoso y eminente es verse, viviendo, andar con buen nombre por las lenguas de las gentes, impreso y en estampa" $(V, 68)$, ¿qué contento podía sacar don Quijote de un libro que "temíase no hubiese tratado sus amores con alguna indecencia" ( $V, 66)$, que se valió de "novelas y cuentos ajenos, habiendo tanto que escribir en los míos" $(\mathrm{V}, 78)$ que con sólo "manifestar mis pensamientos, mis sospiros, mis lágrimas, mis buenos deseos y mis acometimientos pudiera hacer un volumen mayor, o tan grande, que el que pueden hacer todas las obras del Tostado?" (loc. cit.). Hasta aquí, entonces, llegó Cervantes en su desviación de la preocupación absurda por la gallardía de su persona del falso Quijote, tocando la cuestión inquietante de la disconformidad entre la idea que tenía de sí mismo don Quijote y lo que otros pensaban de él e incluyendo entre ellos al autor mismo de su ser por la mala cuenta que había dado de su persona.

Si en este punto ya se daba cuenta don Quijote de las opiniones discordantes que circulaban de él, todavía no estaba en condiciones de entretener o expresar sus propias dudas e incertidumbres respecto a su persona. Cervantes le hizo acercarse a esta posibilidad cuando Sancho le presentó a "Dulcinea" en la persona de una labradora. Aquí también parece que Cervantes estaba reelaborando el texto de Avellaneda. Éste había hecho que su Quijote emprendiera la tercera salida como El Caballero Desamorado (IV, 94), habiendo renegado de Dulcinea por la carta desabrida con que ella había contestado a la suya (II, 77). Bastante más tarde, don Quijote tropezó con la cincuentona Bárbara de la bellaquísima cara (XXII, 295) a quien comenzó a servir como la "soberana señora y famosa reina Zenobia" (XXII, 296), paseándose con ella como si lo fuera, aunque era tan bien conocida su mala fama como evidente su mala facha. Esta sustitución de Dulcinea por la Bárbara-Reina Zenobia, que le sirvió a Avellaneda repetidas veces para poner en ridículo a su Quijote, parece haberle ofrecido a Cervantes la materia prima del problema más desconcertante que había de afligir a su hidalgo mientras se acercaba a la muerte. En vez de repetir la locura fantástica del encuentro con Bárbara-Zenobia del falso Quijote, Cervantes hace que Sancho, como otro Chanfalla del Retablo de las maravillas, le anuncie a don Quijote que está en presencia de "Dulcinea", acompañada de dos doncellas, a quienes el escudero describe con todos sus adornos de joyas y ricos vestidos y montadas "a caballo sobre tres cananeas [sic por "haca- 
neas"] remendadas, que no hay más que ver" (V, 186-7). Ahora le toca al Quijote cervantino no ver más que a tres labradoras, bárbaras en su aspecto ya que no de nombre, lo que da ocasión para que el hidalgo experimente una perplejidad radical que no ha conocido hasta ahora. Mientras Sancho le obliga a arrodillarse ante la señora de sus pensamientos, don Quijote reconoce por primera vez que él puede ser víctima de un engaño "ya que el maligno encantador que me persigue, ... ha puesto nubes y cataratas en mis ojos, $y$ para sólo ellos y no para otros ha mudado y transformado tu sin igual hermosura y rostro en el de una labradora pobre" ( $V, 192)$. Pero Cervantes no se contenta con dejarlo así sino se empeña en hacer más problemático el apuro de don Quijote. Pocos renglones más abajo, cuando el cabalıo ha dado en tierra con "la señora Dulcinea", don Quijote se apresura a "levantar a su encantada [sic] señora" ( $V, 193)$, con lo cual Cervantes inicia una oscilación en que se declara alternativamente que ella está encantada y que el encantado es él. Así es que, después que escapan las tres mujeres, don Quijote vuelve a quejarse a Sancho: “¿que te parece cuan maı quisto soy de encantadores? ... pues me han querido privar del contento que pudiera darme ver en su ser á mi señora" para acabar denunciando a estos traidores por "haber vuelto y transtormado á mi Dulcinea" (V, 194-195). Utra vez, al asegurarle Sancho que lo que le pareció a don Quijote albarda en la hacanea de Dulcinea era "silla á la jineta, con una cubierta de campo, que vale la mitad de un reino, según es de rica" se queda exclamando el hidalgo encantado "ique no viese yo todo eso, Sanciro! ... diré mil veces, que soy el mas desdichado de los hombres" $(V, 197)$. Al fin, en el próximo capítulo, Cervantes da la vuelta detinitiva al asunto: los encantadores le han hecho una mala burla a don Quijote "volviendo a su señora Dulcinea a la mala figura de la aldeana" y él va pensativo, no alcanzando a imaginar "qué remedio tendria para volverla á su ser primero" $(V, 199)$. Aunque todavía una vez más dırá don Quijote que el encanto no se extendió a turbar la vista de Sancho para encubrirle la belleza de Dulcinea y que "contra mí solo y contra mis ojos se endereza la fuerza de su venenu" ( $\mathrm{V}, 201)$, el hidalgo se persuade de que Dulcinea está encantada y el problema de desencantarla llega a ser la preocupación constante de su vida. La alternación entre esperanzas de lograr hacerlo y temures de nunca "volverla a su ser primero" se hace la marca principal de su desarrollo espiritual. Después de declarar a los duques que los encantadores seguirán persiguiéndole "hasta dar conmigo y con mis alras caballerías en el profundo abismo del olvido" y que por eso le han quitado sn dama, que para el caballero andante es "el sol con que se alumbra, y el sustento con que se mantiene" (VI, 271), 
acaba haciendo una confesión de lo más desconcertante. Preguntado si puede ser, puesto que nunca la ha visto, que no exista Dulcinea, don Quijote sondea la profundidad de la perplejidad a que ha llegado: "En eso hay mucho que decir ... Dios sabe si hay Dulcinea, ó no, en el mundo, ó si es fantástica; y éstas no son de las cosas cuya averiguación se ha de llevar hasta el cabo" (VI, 272). $\mathrm{Al}$ acercarse el desenlace de la novela, malos agüeros de que "no la has de ver en todos los días de tu vida" (VIII, 307) resuenan mientras don Quijote hace la última entrada en su aldea, y ya en su lecho de muerte no bastan para reanimarlo las nuevas que trae Sansón Carrasco de que Dulcinea está desencantada (VIII, 324). En suma, de esta manera se ha servido Cervantes de la sencilla sustitución avellanedesca de Dulcinea por Bárbara -para fines puramente cómicos- como un hilo central del desarrollo novelístıco de su obra que acaba en la muerte definitıva de don Quijote ${ }^{13}$.

Volviendo al primer momento del encuentro de don Quijote con la labradora-Dulcinea, el germen de incertidumbre y de perplejidad que se ha sembrado en el alma del hidalgo sigue brotando y creciendo en el capítulo siguiente donde tropieza con los recitantes de la compañía de Angulo el Malo, otra adaptación cervantina de un asunto de la obra de Avellaneda. Mientras éste se contentó con hacer que los comediantes se rindieran a don Quijote para que luego le hicieran a él, y sobre todo a su escudero, burlas que tocan en lo grotesco (XXVI, 347-XXVII, 362), Cervantes comenzó encaminando el mismo asunto básico hacia otros fines más complejos.

13 Hace falta señalar otro uso que hace Cervantes del encuentro equívoco de don Quijote con la labradora-Dulcinea. El engaño perpetrado por sancho se vuelve piedra de toque que le sirve a don Quijote para explicar otros engaños que le afligen cuando se ve con Sansón Carrasco, alias el Caballero deı Bosque y el Caballero de los Espejos. Si se empeña el del Bosque en jactarse de haber vencido a don Quijote en singular batalla, éste le explica que los encantadores que son sus contrarios "no ha más de dos días que transformaron la figura y persona de la hermosa Dulcinea del Toboso en una aldeana soez y baja, y desta manera habrán transformado á don Quijote" $(\checkmark, 252)$ a quien dice que venció. Luego, cuando yace tendido a los pies de don Quijote, ahora como el Caballero de los Espejos, y se descubre en él el rostro de Sansón Carrasco, aquél le exige confesar y creer que no pudo ser don Quijote de la Mancha a quien venció "sino ouro que se le parecía, como yo contieso y creo que vos, aunque parecéis el bachiller Sansón Carrasco, no lo sois, sino otro que le parece, y que en su figura aquí me le han puesto mis enemigos, para que detenga y temple el ímpetu de mi cólera" (V, 268). De esta manera despliega Cervantes un encadenamiento de enganos que reciprocamente parecen corroborar su "verdad". Mientras don Quijote se queda sin enterarse del secreto ahi está, descubierto a los ojos del lector, para avisarle cómo pueden ser las "verdades" que se dan en la vida. Para el hidalgo, todo esto sólo sirve como confirmación de que "todo es artificio y traza... de los malignos magos que me persiguen" ( $V, 279)$. 
Todavía están hablando don Quijote y Sancho de la encantada Dulcinea cuando ven acercarse la carreta que lleva figuras de la Muerte, un Ángel, un Emperador, Cupido, el Diablo con otras personas de diferentes trajes y rostros (V, 204 ss.). Don Quijote, siempre dispuesto a acometer cualquier peligro, está para entrar en esta nueva peligrosa aventura cuando, mansamente, le explica el Diablo quiénes son: recitantes que hacen el auto de Las Cortes de la Muerte y que llevan los vestidos de los papeles que representan. Por primera vez don Quijote confiesa ser víctima de un engaño que no es obra de ningún encantador: "así como vi este carro imaginé que alguna grande aventura se me ofrecía; y ahora digo que es menester tocar las apariencias con la mano para dar lugar al desengaño" (V, 207). Pero Cervantes está por llevar el asunto hacia otras consecuencias. A pesar de reconocer don Quijote su equívoco y ofrecerse a los comediantes en lo que pueda serles de provecho, sale el que "venía vestido de bogiganga, con muchos cascabeles" y, esgrimiendo un palo que trae tres vejigas de vaca nimchadas, dando saltos y sonando los cascabeles, aiborota a Rocinante y luego a todos los demás y acaba armando una pelea que deja maltrecho al caballero andante $(\mathrm{V}, 207-209)$. El giro inesperado que na tomado el encuentro con los comediantes ofrece otra nota en el desarrollo de la perplejidad de don Quijote que hallará su plena expresión más tarde al terminar otra aventura equívoca, la del barco encantado. Allí estalla la incertidumbre que se ha ido acumulando en el alma del hidalgo respecto a poder discernir cuál es verdadero asunto de aventura caballeresca y cuál no, cuando declara: "en esta aventura se deben de haber encontrado dos valientes encantadores, y el uno estorba lo que el otro imtenta: el uno me deparó el barco, y el otro dió conmigo al través. Dios lo remedie; que todo este mundo es máquinas y trazas, contrarias unas de otras. Yo no puedo más" (VI, 218-9) .

La aventura de Las Cortes de la Muerte da lugar a consecuencias que ni se le ocurrió a Avellaneda sacar del encuentro de su hidalgo con los comediantes. Para Cervantes, el episodio queda recordado como el "rencuentro de la Muerte" (V, 215) cuando don Quijote y Sancho continúan sus reflexiones, en el capítulo siguiente, sobre lo que les pasó con los comediantes. Esta manera de referirse al asunto no sólo recuerda el auto para cuya representación estaban vestidos los miembros de la compañía, sino también el desenlace que tuvo cuando don Quijote quiso volver al asalto y Sancho procuró detenerle con la observación de que "es más temeridad que valentía acometer un hombre solo á un ejército donde está la Muerte" (V, 212). Esto se enlaza con lo que va a ser el tema de la conversación del hidalgo con su escudero, lo cual a su 
vez sugiere el sentido del fin que Cervantes prepara para su protagonista. Por un momento se detienen en consideraciones sobre la comedia, cuando don Quijote dice que si Sancho no le hubiera impedido volver a la pelea con las figuras de Las Cortes de la Muerte "te hubieran cabido en despojos, por lo menos, la corona de oro de la Emperatriz y las pintadas alas de Cupido" a lo cual el escudero contesta que "nunca los cetros y coronas de los emperadores farsantes. . . fueron de oro puro, sino de oropel ó hoja de lata" ( $\mathrm{V}, 216)$. Don Quijote está de acuerdo en que los atavíos de la comedia son todos fingidos y aparentes, como es la comedia misma. Sin embargo, las comedias son espejos de la vida humana, pues así como al terminar la comedia los actores se quitan los vestidos y ya no son reyes, emperadores, pontífices, etc., y todos los recitantes quedan iguales, así "cuando se acaba la vida, á todos les quita la muerte las ropas que las diferenciaban, y quedan iguales en la sepultura" (V, 217). Desde luego, Cervantes ha introducido aquí un tópico de largo abolengo pero lo ha hecho sin el acento moralizante o religioso que normalmente lo acompaña. No ha tocado la nota que todavía se encontrará, unos veinte años más tarde, en El gran teatro del mundo de Calderón, donde lo que importa es hacer bien cada uno su papel para merecer el premio que se puede ganar al acabarse la comedia de la vida humana. Por su parte, Cervantes se limita a indicar que la vida no es más que el papel que se desempeña en ella y, al compararla al papel que se juega en la comedia, donde todo es fingido y aparente, parece minar la realidad metafísica de la vida. Lo mismo se repite con la comparación que hace Sancho entre la vida y el juego del ajedrez, "que mientras dura el juego, cada pieza tiene su particular oficio; y en acabándose el juego, todas se mezclan, juntan y barajan, y dan con ellas en una bolsa, que es como dar con la vida en la sepultura" $(\mathrm{V}, 217)$. A estas sugestiones de que la vida no tiene más validez ni mayor trascendencia que el papel que se desempeña en una comedia, hay que añadir otro detalle que se saca de lo que les pasó a don Quijote y Sancho con la compañía de Angulo el Malo. La manera de presentarse el episodio de Las Cortes de la Muerte parece indicar que si, como después se insinúa, la vida no es menos fingida y aparente que la comedia, sin embargo no hay otra vida que ésa ni otra actuación del hombre en ella sino la que corresponde al papel que hace en el "teatro del mundo". Después de todo, el hidalgo y su escudero tuvieron que reñir no con los comediantes, sino con las figuras que representaban. No había bastado que el Diablo explicara, mansamente, quiénes eran él y los otros de la compañía, pues al fin y al cabo hizo su oficio el que "venía vestido de bogiganga" para armar una pelea en que don 
Quijote y Sancho se vieron apedreados por la Muerte, el Emperador, el Diablo, etc. $(V, 21 \mathrm{l})$. Así, aunque todavía germinal y subyacente, estaba por brotar de este episodio la idea de lo decisivo que es darse a un papel en la vida de la comedia humana porque después es difícil, si no imposible, poder deshacerse de la máscara.

Repetidamente, y de diversos modos, Cervantes vuelve a tocar esta idea tan importante para el desenlace de su novela en que dejará a su protagonista "finalmente muerto". Cervantes juega con esta idea en la escena en que Sansón Carrasco, empeñado en vencer a don Quijote para curarle de su locura caballeresca, salió vencido por el loco hidalgo. Al molido y triste Caballero de los Espejos, le hace reparar Tomé Cecial en que "con facilidad se piensa y se acomete una empresa; pero con dificultad las más veces se sale della" y termina preguntando, "¿cuál es más loco: el que lo es por no poder menos, ó el que lo es por su voluntad?" (V, 274). Carrasco quiere insistir en la diferencia entre los casos que señala Cecial: "el que lo es por fuerza lo será siempre; y el que lo es de grado lo dejará de ser cuando quisiere". Pero cuando el que fue loco por su voluntad, haciéndose escudero de Sansón, quiere dejar de serlo y volver a casa, el que fue vencido como el Caballero de los Espejos no se ve con la misma libertad. Volver él a casa "hasta haber molido á palos á don Quijote es pensar en lo excusado; y no me llevará ahora á buscarle el deseo de que cobre su juicio, sino el de la venganza; que el dolor grande de mis costillas no me deja hacer más piadosos discursos" (V, 274). Y, efectivamente, Tomé Cecial se fue y Sansón "quedó imaginando su venganza" $(V, 275)$.

Quizás la presentación literaria más hábil de cómo llega a ser inseparable el hombre del papel de vida a que se ha dado ocurre en el episodio del retablo de Maese Pedro, cuyo entretejimiento con el cuento de los rebuznadores ejemplifica la idea cervantina que vamos señalando. El propósito de Cervantes comienza a encarnarse literariamente al encontrarse don Quijote con el soldado que va a defender su pueblo que, por haber ganado fama de rebuznador, se ha visto objeto de las burlas de los pueblos vecinos. Después de dar cuenta el soldado del gracioso origen de tal disparate y de las repetidas batallas a que ha dado lugar "sin poderlo remediar rey ni roque, ni temor ni vergüenza" (VI, 140), termina con el anuncio de que dentro de un par de días se librará una de esas batallas y es a ella que él se dirige ahora. Cervantes deja pendiente el asunto en este punto para dar lugar a la entrada de Maese Pedro con el mono adivino y el retablo de la libertad de Melisendra. Aquí lo que nos interesa es el retablo que, como ya se ha notado, sirve a Cervantes para retocar a su manera, la escena avellanedes- 
ca de la intervención de don Quijote en la acción de una comedia de Lope. En vez de repetir la escena burlesca de la obra de Avellaneda en que "la risa de los comediantes era notable" (XXVII, 361) ${ }^{14}$ Cervantes desvía lo cómico del asunto hacia un fin más serio. Al comenzar el retablo Cervantes destaca la plena conciencia que tiene don Quijote de estar presenciando una obra fingida. Así es que don Quijote amonestará al trujamán para que respete la línea recta de la historia, sin detenerse en comparaciones entre el sistema judicial de los moros y el de los cristianos (VI, 160-1). También indica estar enterado de la naturaleza del espectáculo cuando expresa su acuerdo con la respuesta que recibe de Maese Pedro a su objeción a la impropiedad de presentar moros que usan campanas en vez de atabales: "No mire vuesa merced en niñerías, señor don Quijote, ni quiera llevar las cosas tan por el cabo... ¿No se representan por ahí, casi de ordinario, mil comedias llenas de mil impropiedades y disparates, y, con todo eso, corren felicísimamente su carrera, y se escuchan, no sólo con aplauso, sino con admiración y todo?" (VI, 165). Sin embargo, a pesar de toda la lucidez que ha desplegado, diez renglones más abajo lo fingido se hace real para don Quijote. Conmovido por la huida de "los dos católicos amantes", Gaiferos y Melisendra, el valiente caballero saca la espada contra tanta morisma que los persigue y no deja de llover cuchilladas hasta dejar destrozadas todas las figuras del retablo. Llegado a este punto, Cervantes todavía da otra vuelta al asunto dándonos a entender que la vida de don Quijote ya no puede ser otra que la de un caballero andante, aunque sea como uno que constantemente descubre incertidumbres que pueden acabar con su carrera caballeresca. Así es que, a Maese Pedro que llora la pérdida de su hacienda titiritera, don Quijote confiesa creer ahora lo que muchas veces había sospechado. Resulta que, a diferencia del hidalgo de la Primera Parte, que vio la transformación de gigantes en molinos de viento como obra de encantadores que quisieron robarle la gloria de una victoria sobre ellos (I, 192-3), don Quijote entiende ahora "que estos encantadores que me persiguen no hacen sino ponerme las figuras como ellas son delante

14 Recuérdese que cuando el loco saca la espada para defender el honor de la reina de El testimonio vengado, el hijo calumniador de su madre responde arrojándole un ataharre y le desafía a alzar "esa mi rica y preciada liga, en gaje y señal de que sea nuestra batalla delante Su Majestad para el tiempo que tengo dicho" (XXVII, 359). Luego, mientras se ríen los comediantes, don Quijote y Sancho discuten si es la "preciada liga del hijo del rey" o un sucio ataharre que el hidalgo quiere guardar en la maleta entre la ropa blanca. La escena termina con la salida del labrador que reclama su ataharre y acaba dándole a don Quijote "un empellón tal en los pechos, que le hizo caer con él de espaldas, y saltándole encima, le quitó por fuerza el ataharre" (XXVII, 360). 
de los ojos, y luego me las mudan y truecan en las que ellos quieren" (VI, 170). Por eso no es culpa suya el yerro que cometió de destruir las figuras del retablo "sino de los malos que me persiguen" (V, 170). Pero al ir a pagar las figuras destrozadas, aun reconociendo el engaño que le hicieron sus enemigos, don Quijote se niega a pagar la de Melisendra ya que ella y Gaiferos estarán "por lo menos, en la raya de Francia; porque el caballo en que iban á mi me pareció que antes volaba que corría" (VI, 173). El astuto Maese Pedro entiende la vuelta del hidalgo a "su primer tema" y concediendo que "no debe de ser Melisendra, sino alguna de las doncellas que la servían", se contenta con sacar sesenta maravedís por ella $(\mathrm{V}, 173)$.

Terminado este episodio en que se vio a don Quijote como inseparable de su "tema", Cervantes reanuda el cuento de los rebuznadores cuyos protagonistas no están menos aferrados a su tema. Irónicamente, aquí le toca a don Quijote exponerles el disparate en que están por meterse. Al escuadrón armado de rebuznadores que espera, con su "estandarte del asno" levantado, al ejército de sus archienemigos, explica el engaño de tenerse por afrentados, "porque ningún particular puede afrentar á un pueblo entero" (VI, 184) . L.e escuchan atentamente mientras declara las causas de la guerra justa, entre las cuales no se incluyen niñerías "que antes son de risa y pasatiempo que de afrenta" (VI, 188). Puesto que al comenzar, el hidalgo les había prometido que con la más mínima señal de disgusto o enfado que hicieran, pondría él "un sello en mi boca" (VI, 183), ahora, con el silencio que le prestan, parece que van quedando convencidos de la razón de don Quijote - como quedó él respecto a la razón del retablo de Maese Pedro. Pero súbitamente surge la incitación que les hace volver a su "tema". El diablo mueve a Sancho a recalcar la lección de su amo sobre la necedad de afrentarse por rebuznos y, recordando la gracia con que lo hacía de niño "sin que nadie me fuese á la mano", suelta un rebuzno de los suyos. Allí estalla la guerra, creyendo que Sancho se burlaba de ellos, y la furia que los rebuznadores guardaban para sus enemigos queda descargada en las espaldas del escudero (VI, 190-191). Así se queda el lector con el quid est demostrandum cervantino respecto a la ineficacia de explicaciones y razonamientos para disuadir a los hombres de las locuras que viven.

El enlace del episodio del retablo de Maese Pedro con la aven. tura de los rebuznos también señala la importancia de entender que, en la novela cervantina, don Quijote no es el único que se presenta como "loco con su tema". No sólo los rebuznadores, sino también otros personajes aparecen apegados de tal manera a un propósito que llevar a cabo o a un papel que desempeñar que Cervantes puede jugar con la integridad de su cordura. Ya se ha 
visto cómo quedó Sansón Carrasco al pretender, como Caballero de los Espejos, curar a don Quijote de su locura caballeresca. Al otro extremo está el caso del Caballero del Verde Gabán, don Diego de Miranda, que se ocupa de vivir sin preocupaciones, un anhelo de tranquilidad que se hace otro sueño de vida en peligro de turbarse por tener don Diego un hijo poeta "que, á no tenerle, quizá me juzgara por más dichoso de lo que soy" (V, 287-29l). El primo anónimo que se dice ser "humanista" de profesión y que se da a la averiguación de cuestiones como quién fue la Giralda de Sevilla, quiénes los Toros de Guisando, quién el primero que tuvo catarro en el mundo, etc., etc., se presenta como una especie de "curioso impertinente", entre necio y loco, de la Segunda Parte, cansándose, según dice don Quijote, "en saber y averiguar cosas, que después de sabidas y averiguadas, no importan un ardite al entendimiento ni á la memoria" (VI, 80). Tampoco a los duques, tan empeñados en burlarse del loco hidalgo y de su escudero -obsesión necia que se vuelve su única razón de ser en la novela-deja Cervantes escaparse ilesos. En el momento de conceder a Sancho la anhelada ínsula que gobernar -anticipo de las burlas que le harán a él y a su amo- se atreve el eclesiástico a jurar por el hábito que trae que el duque "es tan sandio... como estos pecadores. ¡Mirad si no han de ser ellos locos, pues los cuerdos canonizan sus locuras!" (VI, 261). Más adelante, al comenzar la burla de la muerte de Altisidora, Cervantes informa al lector que Cide Hamete "tiene para sí ser tan locos los burladores como los burlados, y que no estaban los Duques dos dedos de parecer tontos, pues tanto ahínco ponían en burlarse de dos tontos" (VIII, 268). Con todo esto, Cervantes añade otro argumento a su "polémica literaria" con Avellaneda. Pues si éste separó absolutamente a don Quijote de los demás personajes de la obra, encerrándole en su locura sin relieve para hacerle el hazmerreír de los cuerdos, Cervantes iba cerrando la brecha entre el hidalgo y los otros en el sentido oue hemos indicado, haciendo a todos figuras de la misma gran comedia humana.

Sin embargo, en otro sentido, sí logró Cervantes trazar una diferencia fundamental entre don Quijote y los otros personajes de la novela, entregándolo a una locura de alcance mayor, al lado de la cual las preocupaciones de los demás parecen bastante limitadas. Es esto precisamente lo que le hace digno de la muerte que su autor le tiene reservada, pues su vida caballeresca padece dudas radicales que reflejan las incertidumbres que pueden afligir toda vida humana. Ya vimos cómo en sus andanzas don Quijote puede tropezar con cuestiones de si las cosas son verdaderamente lo que parecen ser y si las discrepancias entre su ser y su parecer se deben a fuerzas ("encantadores") que obran sobre la realidad o sobre la 
persona que la percibe. Como caballero andante, don Quijote también tiene que vivir confrontaciones con otros individuos que no aceptan la realidad del mundo en que él vive y le toca y el problema de arreglárselas con ellos, sea para justificar su vida, sea para explicar por qué los otros no ven o no entienden la realidad que él vive, sea para quedarse en la perplejidad de no saber hacer ni una cosa ni otra. Como ya queda señalado, no será el menor de los problemas que le aflige el del ser y existir de Dulcinea -es decir, si la Dulcinea a quien dedica todos los pensamientos y las acciones de su vida realmente existe tal y como él la concibe. Aquí, no hace falta mucho para reconocer el reflejo del problema que puede afligir a todo hombre que se propone entregar su vida al servicio de su Dios. En fin, es el encuentro con problemas de esta magnitud que marca el camino de don Quijote hacia su segunda y definitiva muerte.

Mientras el hidalgo sigue por este camino, todavía le esperan momentos de triunfo, aunque sean a veces equívocos, que parecen confirmarle en la verdad y el valor de su vida caballeresca. Entre ellos hay que incluir la victoria sobre El Caballero de los Espejos, la valentía que despliega desafiando al león, la misión que lleva a cabo volando por el aire montado en Glavileño y su rendimiento de Tosilos. Pero también se tocan notas más sombrías, que anuncian el fin melancólico a que se dirige. Además de las perplejidades e incertidumbres que han comenzado a afligirle, quizás tengamos el primer atisbo del desengaño final de don Quijote en su descenso a la cueva de Montesinos. Para darse cuenta cabal de la importancia de esta aventura, hay que recordar el cuento esperanzado del Caballero de Lago que todavía pudo narrar don Quijote en la Primera Parte. Allí, respondiendo a las dudas del canónigo, don Quijote le pintó la gloria que podía esperar un valiente caballero andante. El valor del caballero que se lanza en "el gran lago de pez hirviendo á borbollones" recibe su galardón al salir "entre floridos campos; con quien los Elíseos no tienen que ver en ninguna cosa" (IV, 276-278). Al Caballero del Lago le reciben doncellas que le llevan a un maravilloso castillo donde le agasajan con baños, olorosos ungüentos, lujosos vestidos, sabrosos manjares, música y relatos de encantamientos que le suspenden el alma (IV, 279-282). Esta apoteosis del caballero andante, esperanza halagadora de la Primera Parte, se hace experiencia sombría de la vida de don Quijote en la Segunda Parte. En la descripción de su descenso a la cueva de Montesinos, don Quijote parece estar por repetir lo del Caballero del Lago: "me hallé en la mitad del más bello, ameno y deleitoso prado que puede criar la naturaleza, ni imaginar la más discreta imaginación humana... Ofrecióseme luego á la vista un real y suntuoso palacio ó alcázar, cuyos muros y 
paredes parecían de transparente y claro cristal fabricados" (VI, 90-91). Pero pronto el principio halagador cede a escenas de una melancolía sin relieve. A don Quijote no le reciben doncellas, sino el anciano Montesinos, todo gravedad, vestido de colores sombríos, de una barba canísima, y que, en vez de armas, trae un rosario. Aquí no habrá banquetes y agasajos. Montesinos lo lleva al sepulcro de Durandarte, sobre el cual yace "tendido de largo á largo, no de bronce, ni de mármol, ni de jaspe hecho... sino de pura carne y de puros huesos" (VI, 93). A Montesinos y a Durandarte, así como a Belerma y a la misma Dulcinea que pronto aparecen, a todos tiene encantados Merlín, el encantador francés que siendo hijo del diablo, según dicen, supo un punto más que su padre. Cómo o para qué los encantó, nadie lo sabe pero "ello dirá andando los tiempos, que no están muy lejos, según imagino", dice Montesinos (VI, 94).

Si desconciertan la tristeza del ambiente encantado de la cueva de Montesinos y el no saber con qué fin es así, aún más desconcertantes son las notas realistas que se introducen: al corazón de Durandarte, que pesa dos libras, hay que echarle sal para que no hieda (VI, 97) ; Belerma se ve descompuesta y fea, y con aspecto de sufrir "el mal mensil, ordinario de las mujeres" (VI, 100-102); Dulcinea necesita seis reales, aunque todavía se ve encantada como labradora (VI, 109). A pesar de la melancolía de la escena, y las notas realistas que ponen en peligro la integridad del ambiente encantado, don Quijote, todavía fuerte en su sueño caballeresco, ha vivido el descenso a la cueva como "la más sabrosa y agradable vida y vista que ningún humano ha visto ni pasado" (VI, 86).

En otras condiciones le encontramos cuando se está acercando al final de su carrera - aun antes de sufrir el golpe decisivo a manos del Caballero de la Blanca Luna- según se ve en su encuentro con los labradores que llevan imágenes de santos que han de servir para un retablo. Don Quijote se detiene ante ellas para celebrar las virtudes de los santos representados, todos a caballo: San Jorge, con la serpiente enroscada a sus pies, "fue uno de los mejores andantes que tuvo la milicia divina... además defendedor de don. cellas"; San Martín, también a caballo, repartiendo su capa con el pobre, "fue más liberal que valiente"; Santiago, "la espada ensangrentada, atropellando moros y pisando cabezas", fue uno de los más valientes santos y caballeros que tuvo el mundo; San Pablo, caído de su caballo en el momento de su conversión, fue "el mayor enemigo que tuvo la Iglesia de Dios Nuestro Señor en su tiempo, y el mayor defensor suyo que tendrá jamás" (VIII, 49-50). A todos estos santos caballeros, don Quijote los ve profesando, como él, el ejercicio de las armas, con la diferencia de que ellos fueron santos y pelearon a lo divino, conquistando el cielo a fuer. 
za de brazos, porque el cielo padece fuerza. Pero él, pecador, pelea a lo humano y "hasta agora no sé lo que conquisto a fuerza de mis trabajos" (VIII, 51). La esperanza de mejorar su ventura y de encaminar sus pasos por mejor camino del que lleva si Dulcinea se libra del encantamiento, queda malograda. Seis capítulos más adelante, don Quijote se ve vencido por el Caballero de la Blanca Luna, todavía defendiendo la fama de Dulcinea (VIII, 190-191).

Cervantes hace decisiva la derrota de don Quijote, presentándola como la culminación de sus inquietudes; al poner fin a sus andanzas caballerescas, le dejan sin otra vida que vivir: "Si muchos pensamientos fatigaban á don Quijote antes de ser derribado, muchos más le fatigaron después de caído... unos iban al desencanto de Dulcinea, y otros á la vida que había de hacer en su forzosa retirada" (VIII, 221). Respecto a lo primero, a pesar de creer que Sancho había cumplido con lo de darse los azotes necesarios para desencantar a Dulcinea, malos agüeros le entristecen a la entrada de su aldea, advirtiéndole "que no la has de ver en todos los días de tu vida" (VIII, 307). Por lo que toca a lo segundo, todavía le permite Cervantes a don Quijote soñar con la posibildad de una nueva vida pastoril (VIII, 224-227). Pero se desvanece toda posibilidad de vida nueva, junto con la de volver a la caballería andante, al despertar doblemente del sueño - del dormir y de la vida quijotesca - con la conciencia de que "ya en los nidos de antaño no hay pájaros hogaño" (VIII, 328). Así, juntándose con la idea de que la vida es una comedia en que todos hacen su papel la de que a cada uno sólo le es dado un papel que desempeñar, al ir don Quijote a abandonar el suyo de caballero andante, por desengañado y vuelto a la cordura, se le ve acercándose a la muerte. Aún antes de despertarse de su sueño, el médico dio su parecer de que al hidalgo "melancolías y desabrimientos le acababan" (VIII, 321). Ahora, despertado como Alonso Quijano, el cura expresa la opinión que tienen todos los circunstantes: "Verdaderamente se muere, y verdaderamente está cuerdo Alonso Quijano el Bueno; bien podemos entrar para que haga su testamento" (VIII, 325). Sancho, a distinción del escudero avellanedesco de quien el falso Quijote se separó apenas dándose cuenta de su ausencia (XXXVI, 453), se queda al lado del hidalgo de Cervantes hasta que se muere -o, como dice el lloroso escudero mientras le implora que no se muera - hasta dar en "la mayor locura que puede hacer un hombre en esta vida" que es "dejarse morir, sin más ni más, sin que nadie le mate, ni otras manos le acaben que las de la melancolía" (VIII, 327).

En fin, a umbrales de la muerte de su protagonista, Cervantes está constantemente llamando la atención a lo particular de lo que ha realizado en su novela. Nada nuevo hubo en hacer el autor 
que encontrara la muerte un personaje en una obra literaria. Lo nuevo, y el corazón mismo que late en el arte novelístico de Cervantes, fue llevar al caballero andante a la tumba por un camino a lo largo del cual se jugaba el sentido y la validez que tenía para don Quijote su propia vida -dejando para el lector el vivir la problemática de los otros personajes, incapaces de la profundidad existencial del hidalgo. Así, lo de haber dejado a don Quijote tendido largo a largo en la tumba e imposibilitado de resurrección para otra salida y nuevas aventuras, fue más que un dardo retórico que Cervantes lanzó a su rival. Quijano murió cuando se deshizo la razón de ser, el papel de vida, de don Quijote, dejando al hidalgo, en efecto, encerrado con dos llaves en una muerte definitiva. En todo esto, a Avellaneda, que hizo florecer precisamente lo que intentó aplastar, proporcionando, como hemos visto, el estímulo y materias cruciales para el desarrollo de la novela cervantina, se le debe el agradecimiento de haber escrito la obra más magníficamente contraproducente que ha conocido la literatura española.

A. A. Sicroff

Queens College, City University of New York. 